\title{
El tractament de la dona com a pensadora en l'Aplec de rondaies mallorquines d'Antoni M. Alcover
}

\author{
M. Magdalena Gelabert i Miró \\ Universitat de les Illes Balears \\ mmgelabert@gmail.com
}

\begin{abstract}
RESUM
En l'Aplec de Rondaies d'Antoni M. Alcover apareixen tipus de dones molt diverses. Hi trobam dones que es presenten des de la perspectiva de la intel-ligència i és la seva capacitat intel-lectual un dels trets principals que les caracteritza. Aquestes dones tant poden pertànyer a la reialesa —o a classes socials altes - com a la pagesia; tant poden ser joves com velles; fadrines com casades. La capacitat de pensar de les dones i el seu enginy fan que, en moltes ocasions, superin les figures masculines i que siguin elles les que donin la solució als problemes que sorgeixen al llarg de la trama. Amb l'anàlisi d'exemples diversos de l'Aplec d'Alcover. observam com la dona és considerada una figura de prestigi que mereix ser respectada per la seva capacitat de pensament i per la saviesa.
\end{abstract}

PARAULES CLAU

Rondalla; dona intel-ligent; dona sàvia; figures femenines; Alcover

\begin{abstract}
Many types of women are portrayed in the Aplec de Rondaies by Antoni M. Alcover, some of whom are notable for their intelligence, and intellectual ability. These women may belong either to royalty and the upper classes or to the lower classes; they may be young or old and single or married. Through their perspicacity and resourcefulness, these women are frequently able outdo their male counterparts and find solutions to problems that emerge throughout the story. The following analysis of different examples from the Aplec by Alcover shows how the women in these stories are portrayed as figures of prestige who deserve to be respected for their intellectual ability and wisdom.
\end{abstract}

KEYWORDS

Folktale; intelligent women; wise women; female figures; Alcover

REBUT: 25-08-20I7 | ACCEPTAT: I3-09-20I7 


\section{La diversitat de dones de l'Aplec d'Alcover}

Les dones que apareixen en l'extens aplec de rondalles ${ }^{\mathrm{I}} \mathrm{d}^{\prime}$ Antoni M. Alcover (Manacor, I862-Palma, I932) són molt diverses i riques en matisos. Formen un ventall molt gran de personatges que corresponen a sectors socials diferents i a situacions variades. No hi ha límits per a les dones, més enllà dels propis de valors ètics que permeten la convivència en societat. Hi ha dones joves i velles, bellíssimes i lletges, extremadament intel-ligents i bambes, obedients i rebels, amoroses i desenfreïdes, dòcils i caparrudes, ben vestides i gairebé despullades, mares i madrastres, sogres, fadrines, casades, gegantes, bruixes, fades, pageses, reines i un llarg etcètera.

En general, els personatges de les rondalles són dibuixats de manera plana, sense gaire descripció psicològica i marcats amb trets molt generals i radicalment oposats uns dels altres, de tal manera que siguin fàcilment identificables amb els models i estereotips que el narrador vol transmetre. Això es produeix a causa de l'estil abstracte que caracteritza les rondalles d'arreu del món i també pel fet de provenir, de manera més o menys propera en el temps, de produccions orals.

Els personatges es descriuen de manera clara i amb atributs que els caracteritzen fàcilment i que els fan identificables amb un cop d'ull. Ja ens diu Lüthi que «Nel piano mondo della fiaba le singole figure risaltano e si distinguono esteriormente grazie ai loro nitidi contorni e ai loro colori pure» (I979: 37). Hi afegeix: «I personaggi della fiaba non sono fatti di carne e ossa, di una materia duttile, capace di adattarsi, in cerca di raporti, bensí di qualcosa di compatto, rigido e isolante» (I979: 53). En les rondalles d'Alcover no és exactament així, ja que els personatges són més descrits del que és habitual a causa de la potència de la seva intervenció com a escriptor.

\section{Contra els prejudicis i tòpics: l'astúcia i la intel-ligència de les dones en les rondalles}

Caterina Valriu, en un apartat titulat «La rondalla com a visió del món a través de la dona» (I998: 9I-94), rebat el prejudici, produït probablement per una lectura poc aprofundida, que atribueix a les rondalles uns esquemes de pensament i de comportament masclistes. Parla sobre el paper actiu i destacat de la dona, quant a personatge de les rondalles i també com a transmissora. Al final, però, conclou: «Les rondalles parlen d'una realitat psíquica humana que sovint és comuna a ambdós sexes, d'uns processos psicològics, d'uns sentiments i unes reaccions que es donen per igual entre homes i dones» (I998: 94). També ho diu Temporal de manera clara: «La primera conclusió ben fonamentada, des del punt de vista de la relectura del mode nuclear, és que la rondalla meravellosa no estableix cap diferenciació antropològica entre heroïna i heroi» (20I4: I84-I85).

Tant en la vida real com en les rondalles, sovint la dona ha hagut d'amagar la intel-ligència i els coneixements que té, fins i tot la seva bellesa, perquè sap que això provoca reaccions en l'home, que intenta anul-lar el seu paper tot sometent-la, obligant-la a fer determinades tasques o tancant-la dins una torre. La dona

I El corpus que hem analitzat en la nostra investigació en comprèn 433, tot i que no totes corresponen al gènere de la rondalla, sinó que també s'hi inclouen llegendes, anècdotes, etc. que Alcover agrupà en un sol recull. 
ha hagut de crear estratègies per poder sobreviure dins un món de paràmetres andrògins a fi de no perdre la personalitat pròpia. Així, ha hagut d'usar l'astúcia, el silenci o la persuasió per poder escapar de situacions perilloses i desagradables. Mireille Piarotas (I996) distingeix dos tipus d'astúcia, l'ofensiva i la defensiva. La dona usa la primera per aconseguir alguna cosa que vol, per exemple anar-se'n del ball d'hora per augmentar l'interès del príncep; la defensiva és per deixar de fer alguna cosa a la qual se l'obliga, per exemple, demanar proeses amb la intenció de guanyar temps per no casar-se amb el fals heroi o amb qui ella no vol.

El nom i el prestigi de determinades dones fa que siguin conegudes i temudes pertot arreu, aquest és el cas de la reina d'Ongria. El pare d' «Es tres patrons», ALC. M. XI (I996: II8-I3I), ${ }^{2}$ adverteix els seus fills que no s'atreveixin a anar al Port de la Reina d'Ongria, però la prohibició és incomplerta i els tres joves patrons acaben a les mans de la reina. Ella els posa messions i només el tercer, gràcies als advertiments dels seus germans que troba casualment al Port, serà capaç de superar la messió i de no sucumbir a l'efecte dels dormissons que ella els posa en el sopar. La figura de la reina d'Ongria representa la dona fatal, temuda per la seva intel.ligència —que s'expressa, sobretot, amb la seva eloqüència- i pel seu poder que pot superar el de qualsevol home.

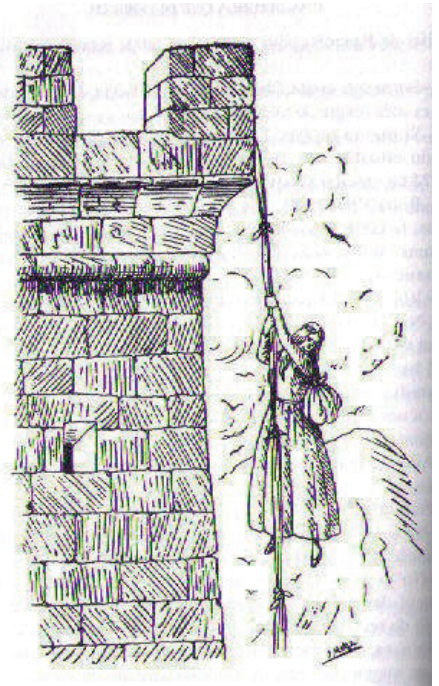

[Imatge I : Na Catalineta, la protagonista d'«Una gírgola que dugué coa», aconsegueix fugir del gegant]

$2 \mathrm{Al}$ llarg del present article, les citacions de les rondalles s'indiquen de la manera següent: en primer lloc, figura el títol de la rondalla i el tipus rondallístic, a continuació hi ha el nom de l'autor amb l'abreviació ALC. seguida per les lletres GG., quan es tracta de l'edició crítica de Josep A. Grimalt i Jaume Guiscafrè, o M. quan el volum forma part de l'edició popular de Francesc de B. Moll. Posteriorment, s'esmenta en numeració romana el número de volum: I-VII, per a l'edició de Grimalt i Guiscafrè, i I-XXIV, per a l'edició de Moll. Per acabar, s'inclou entre parèntesis l'any d'edició i la pàgina o les pàgines corresponents de la rondalla. Per a les citacions de les llibretes manuscrites, s'afegeix a l'abreviació ALC. l'abreviatura Lta. el número de plagueta corresponent en numeració romana: I-VI. Per al tipus rondallístic —en el cas d'aquesta rondalla no figura - s'ha consultat, sobretot, l'edició crítica de Grimalt i Guiscafrè i el portal RondCat. 
En «Una gírgola que dugué coa» ATU 3Io ALC. GG. I (I996: 432-456), la protagonista demostra tenir el valor i la intel-ligència suficients, en primer lloc, per aprendre com desfer-se del gegant, com fugir de la torre i esdevenir fada. En segon lloc, per valer-se sola dins un bosc i per travessar els entrebancs que li van sorgint. Aquests es presenten en forma de tres jovenells que pretenen passar la nit amb ella, però na Catalineta no es deixa intimidar i usa els seus poders de fada per ferlos repetir una mateixa tasca tota la nit, de tal manera que ells se n'escaliven i no tornen a molestar-la. Al llarg de la rondalla, observam com el pes i la personalitat de na Catalineta són molt superiors als de tots els altres personatges masculins. També supera els seus germans majors n'Aineta, l'heroïna de «S'abre de música, sa font d'or i s'aucell qui parla» ATU 707 ALC. GG. VI (2013: 207-223), atès que ella és qui aconsegueix els tres elements màgics als quals els seus dos germans no havien pogut arribar.

A través del desenvolupament d'aquests models, es recupera el paper de la dona des d'una perspectiva positiva i se la valora per les seves qualitats intel-lectuals. D'alguna manera, es compensa el pes de la tradició que durant segles ha intentat subjugar la dona al poder dels valors masculins, i ara es planteja una neutralitat que iguala les persones i que posa al mateix nivell el costat masculí i el femení. Marie-Louise von Franz explica que, per desfer el camí errat, basta seguir els principis de la Càbala:

Par ailleurs, on connaît la version biblique selon laquelle la mort et la corruption sont apparues dans le monde par la faute d'Eve, et nous avons vu qu'une doctrine s'est dévelopée dans la Kabbale, où il est dit que cette satisfaction insatisfaisante est le résultat de la séparation qui s'est produite entre la Shekhina et Dieu: si le principe féminin était réhabilité et rejoignait la divinité, le monde retrouverait une harmonie. Si nous transpossons sur le plan psychologique le sens de ces contes et de ces mythes, nous dirons que ces quelques exemples illustrent la blessure et l'appauvrissement psychiques qui découlent du refoulement et du mépris dans lequels est tenu, le plus souvent, le principe féminin. S'est pourquoi l'être humain sage et religieux et tous ceux qui s'efforcent de faire progresser la conscience travaillent à sa restauration et à elle de la hiérogamie ou mariage sacré des principes masculin et féminin (I984: 284-285).

\section{Els nombrosos exemples}

L'objectiu implícit en les rondalles és aquest mateix: el de donar el protagonisme adequat i equilibrat a les persones, independentment del seu sexe, tot fent camí en la restauració dels valors igualitaris universals. En moltes de les rondalles de l'Aplec d'Alcover, la dona hi apareix representada com a model d'intel-ligència i el seu prestigi intel-lectual és reconegut i compartit per la resta de personatges.

Algunes ja comencen presentant la dona a partir d'aquest tret, que és el que marcarà tota la trama, tal és el cas d' «En Pere tort» ATU 85I ALC. M. XVI (I997: 75-95): «Això era un rei que només tenia una fia, s'al-lota més llesta i sabuda que escaufava el sol. Sabia d'es llim de ses olles, tenia llengo per setze, i per coses envitricollades que li diguessen, mai la porien confondre ni capturar». Son pare fa unes dictes que es casarà amb ella aquell que li digui una endevinalla que ella no 
sàpiga resoldre i «Ja ho crec que començaren a presentar-s’hi fadrins i més fadrins, i hi anaven els més desperts i que pretenien més de cames primes; i bé n’hi deien, d'endevinaies enrevisclades i fondes; però ella, encara no les hi acabaven de dir, com ja los ho entimava p'es morros, desllatigades», i encara afegeix una mica més endavant: «I per molts que n'hi anassen, i per desxondits que fossen, a tots sa fia del rei los deixava en es siti» (I997: 75).

El plantejament és clar des del principi: la ment de la dona supera amb escreix la dels homes més intel-ligents, no hi ha manera de poder-la guanyar a pensar. Només n'hi haurà un, en Pere, que serà capaç de vèncer-la tot plantejant-li una endevinalla que no sap resoldre, tal jove és descrit de la manera següent:

un begantellot d'un llogaret, Pere de nom, fii d'una pobra viuda, més traïdor que un gat negre, més embuiós que una colla d'escrivans, tort d'un ui, però que en so que tenia condret hi veia més que els altres de quatre en quatre, per dematí que s'aixicassen. I lo bo era que si no el sospesaven bé, pareixia una galina orba, un beninoni, un beneit; però només ho era per no pagar s'hostalatge (ALC. M. XVI [I997: 76]).

Resulta molt significativa l'explicació detallada que Alcover aporta en aquesta rondalla sobre el procés de pensament de la princesa. L'autor es delecta en els detalls de com la dona s'hi implica, amb cos i ànima, de tal manera que, fins i tot els que l'envolten, s'hi veuen immersos. Quan en Pere li diu l'endevinalla per segona vegada:

I ja tornàrem tenir sa fia del rei capficada i pensa qui pensa: un cop fixava els uis en terra, un cop a ses bigues. Allà li hauríeu vist fer-li feina, an aquell cap seu; i lo mateix d'un ca afamegat que li tiren un os, i s'hi aborda amb ses barres, i li clava ses dents, i les se fa croixir amb ses estretes que li pega, si veu que no li pot entrar ni esbrellar-lo, i el tira, i el torna prendre, i el torna tirar, i arriba a estar rabiós de tot, que se tornaria a un puat, lo mateix li succeí a sa fia del rei amb s'endevinaia d'En Pere. Bé n’hi donà, de voltes, bé la se mirà a sen endret i a sen revés, per damunt i per davall, per davant, per darrere i p'es costats: enlloc li afinà llivanya ni li pogué veure gens es demble. Bé s'hi va rompre ses banyes: no la va sebre desgatinyar, ni va sebre per ont hi anaven.

La dona suava a les totes; son pare i sa mare tenien calfreds; tots els de la cort estaven astorats (ALC. M. XVI [1997: 82-83]).

En aquest cas, observam com Alcover usa un to de respecte cap al pensament de la jove, perquè no apareix cap matís irònic ni cap element que denoti dubte sobre la seva capacitat intel-lectual privilegiada. Aquesta mateixa situació s'hauria pogut plantejar des de la visió de la ridiculització de la princesa, que podria quedar vençuda per no haver estat capaç de guanyar el seu adversari, però no és així, al contrari.

Al final de la història, una vegada que en Pere s'ha donat a conèixer, tothom pot comprovar que, encara que físicament tengui mancances i que el seu aspecte no sigui atractiu, està al nivell intel-lectual exigit, tant pel rei com per la princesa. Aquesta darrera demostra, també, la seva intel-ligència amb el fet de reconèixer la vàlua d'en Pere, tot i la seva aparença, perquè ella valora més el fons dels valors humans i del pensament que la forma física, per això accedeix, convençuda, al casament: 
Li feren explicar s'endevinaia, i tothom quedà convençut de que tort poria esser i mig afortunat, però que era més viu que una centella, que donava set voltes a tots es més desperts, que bolcava tothom, i ningú el bolcava a ell; que per estret que se ves, sempre trobava portell o forat per ont sortir, i que per això era s'homo més trempat i més avengut, que era fet a posta per sa fia del rei i per un dia dur sa corona.

Tothom, i el rei primer, trobava que era així; també ho trobà la princesa, que el se començà a mirar amb bon ui i a posar-li voluntat, i arribà a dir:

-Per part meua, mos porem casar en voler (ALC. M. XVI [I997: 95]).

Un cas clar d'intel-ligència i valentia és el de na Catalineta de «Tres germanes i un gigant» ATU 3II ALC. GG. I (I996: 459-474), que s'horroritza davant la cambra de les dones mortes i el safareig de sang, i té un esclató de cor, però al cap de poc temps reflexiona i es refà per poder alliberar-les: «La pobra no pogué pus, i rompé en plors. Plorà una bona estona, fins que va dir: - Ja he plorat prou! I lo que es diu plorant poca carrera faria! Lo que interessa és veure com poré treure aqueixes dues germanes meues d'aquí dins, enc que sia només sa seua còrpora! Sobretot, uis espolsats i fora son!» (I996: 466). Un altre dels exemples més paradigmàtics és el de les dones que apareixen en «Es Castell d'Iràs i no tornaràs» ATU 3I3C ALC. GG. I (I996: 499-527). La rondalla ens explica, a través de la veu sàvia d'una jaieta que aconsella en Bernadet, que el rei d'aquest Castell és molt llest, però la seva dona i la seva filla li guanyen de massa:

-Aquí — diu sa jaia - vendran a rentar un covonet de roba perhom ses tres fies del rei d'es Castell d'iràs i no tornaràs: Na Margalida, Na Rosa i Na Fadeta; si una garrida, s'altra més; però encara sa darrera se'n du sa vantatge. Mira si ho deu ser, garrida i galanxona! Idò encara és molt més llesta i sabuda. Tu mateix ho veuràs per lo que ara et diré. De llest que és son pare, el dimoni fa a mitges amb ell; i sa dona, la reina sap encara set vegades més que el rei. Idò bé, Na Fadeta sap set vegades més que sa mare (ALC. GG. I [1996: 505]).

Les paraules de la jaieta es van confirmant en el transcurs de la rondalla: el rei és molt llest i malvat, com el dimoni; la reina sap veure quines són les estratègies i metamorfosis que ha fet servir na Fadeta per fugir de son pare quan a ell li havien passat per alt; i na Fadeta se'n desfà de tots els obstacles que ha de travessar per tenir una vida feliç amb en Bernadet.

Un altre cas d'intel-ligència superior femenina és el de «La fada Morgana» ATU 428 ALC. GG. III (2OOI: 265-273), ${ }^{3}$ el nom de la qual, tant si se li atribueixen poders positius com malèfics, es relaciona amb la saviesa. La rondalla comença «Això era la fada Morgana, que era reina i molt sabuda», i només vol una jove tan sabuda com ella per a les noces del seu fill. Al final, beneeix la parella perquè la jove ha superat les proves que li ha posat, encara que amb l'ajut del fill de la reina, Beuteusell. ${ }^{4}$ La fada Morgana és un dels personatges més coneguts i emblemàtics del cicle

\footnotetext{
3 Vegeu l'apartat «La importancia de las hadas Morgana y Melusina en los cuentos de D'Aulnoy» dins Zipes (20I4: 73-82). També el capítol titulat «La fada Morgana en la tradició oral mallorquina» dins Jaume Vidal Alcover (I996: 50I-504).

4 Vegeu la reflexió sobre el nom Beuteusell de Josep Antoni Grimalt en ALC. GG. III (200I: 265-266) i la de Jaume Vidal Alcover (I996: 502).
} 
artúric, prové de la mitologia celta i és especialment tractada a l'època medieval. Dins el marc de l'imaginari medieval apareix des de múltiples perspectives, com la de dona fatal o fetillera, com explica Laurence Harf-Lancner (I984: 7-Io i 23-77).

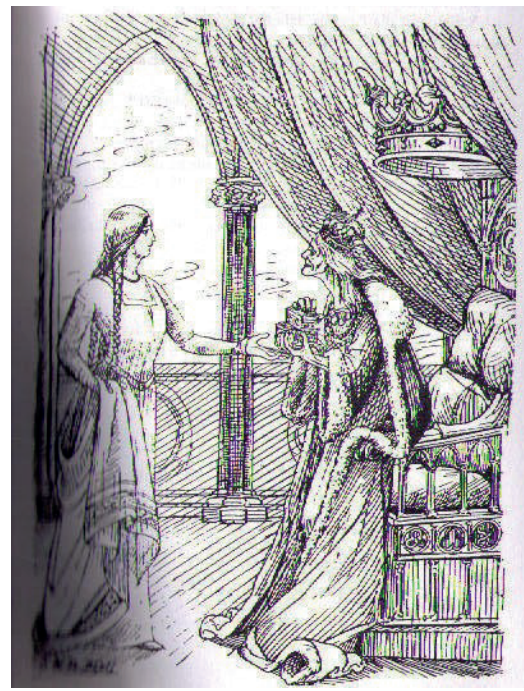

[Imatge 2: Na Joana i la mare de la fada Morgana, en versió de F. de B. Moll]

A «Sa fia d'es carboneret» ATU 92I 875 ALC. M. I (I997: 38-45), na Catalineta enamora el rei amb la seva intel-ligència. Ell considera que és un repte personal aconseguir-la fins al punt que diu «—El diantre és aquesta al.lota! —digué el rei tot admirat-. Mira, si no la puc confondre, m'he de casar amb ella» (I997: 40), talment ho compleix però «va amb uns pactes». El rei posa una condició a la dona: «Que no pots donar conseis a negú — diu el rei-. Si en dónes cap, te n’hauràs de tornar a sa barraca de ton pare» (I997: 40). El rei intenta posar limitacions a la capacitat intel-lectual de la seva futura dona, com si tingués por que pogués ser superior a ell, maldament ella s'enginya per minvar la força d'aquests pactes amb la condició de poder-se'n dur una joia, la que ella triï. La joia elegida és el mateix rei que, una vegada més, constata la superioritat intel-lectual de la seva dona i desfà els pactes: li permet donar consells — «mentres sien bons»- i, consegüentment, pensar i desenvolupar la seva intel-ligència en plenitud. Segons Gala Denissenko:

Les relacions entre el rei i la filla del carboner representen una mena de rivalitat entre els dos personatges, entre un home i una dona, la qual cosa representa el conflicte bàsic en les rondalles d'aquest tipus [rondalles novel-lesques]. L'adversari de la dona en aquestes rondalles és sempre un home (el rei, el fill del rei, el marit...) que li planteja una sèrie de proves. La protagonista se'n surt en tots els casos, demostrant així la seva superioritat sobre l'home (I999: 458).

A més a més, Denissenko conclou:

Les rondalles d'aquest tipus [novel-lesques] perden el to meravellós i tenen un caràcter realista. La protagonista normalment pertany al poble, i la superació de les proves posa de manifest les virtuts i l'enginy de la 
dona. L'heroïna d'aquestes rondalles no utilitza poders màgics ni té objectes meravellosos, però és molt llesta i intel-ligent i, gràcies a això, surt victoriosa de les proves que li posa el seu adversari (I999: 456).

Un exemple similar és el de la rondalla «Una al·lota desxondida» ALC. M. IV (I995: I44-I5O), en la qual el rei —en la versió editada- o un senyor ciutadà —en l'original manuscrit ALC. Lta. V (52-53) - cerquen una al-lota per casar-se que sigui bella i intel-ligent alhora. El pare de l'al-lota i l'home fan plegats el camí des de Palma cap a Manacor i, a mesura que caminen, el segon va fent preguntes i comentaris al primer que aquest no entén de cap manera. Quan arriben a Manacor, el pare el convida a sopar a casa seva amb la seva dona i la filla i, quan el sopar acaba, l'home queda darrere la porta i escolta com el pare conta a la família el que l'altre li ha dit. La jove entén perfectament el perquè de cada una de les preguntes i de les observacions que l'home ha fet al seu pare i les hi explica. Aleshores, l'home es presenta i revela que és el rei i que es vol casar amb la jove per la seva bellesa i, sobretot, per la intel-ligència. Un model semblant és el de «La fia del Sol i de la Lluna» ATU 898 ALC. M. II (I997: 7-28), on la protagonista demostra novament la superioritat intel-lectual de la dona enfront de la del rei, que queda anul-lat davant d'ella, gairebé sense paraula.

Una de les protagonistes femenines més emblemàtiques és «N’Espardenyeta», ATU 879 ALC. M. VII (I995: 87-99), que arriba a casar-se amb el rei perquè s'enamora de la seva intel-ligència i bellesa, encara que l'hagi fet patir amb respostes agressives i dures als seus reptes. Ella és la més atrevida de les candidates a ser esposes del rei. No s'acovardeix pel fet que ell és qui és, sinó que li torna les ofenses multiplicades. És venjativa i enginyosa però, així i tot, el rei l'excusa cada vegada i la troba graciosa: «An el rei li va fer tanta de gràcia aquella sortida, que ja és partit, pegant fua cap avall per s'escala» (I995: 92).

Un altre és el de «Na Tricafaldetes», ATU 327A ALC. GG. II (I998: 65-84), que és «de bona pasta ferm, però més viva que una centella» (I998: 67), preveu que son pare la deixarà abandonada al bosc i cada vegada se'n du alguna cosa per anar tirant pel camí per poder-se'n tornar a ca seva, el que no pogué preveure és la intromissió de la cusseta que es menjà les figues. Quan es troba amb la geganta i el gegant, se les enginya per sortir-se'n i alliberar-se d'ambdós i, a més a més, gràcies a la seva intel-ligència i a l'habilitat per parlar, es casa amb el rei.

\section{La intel-ligència de les jaies}

Els exemples d'intel-ligència femenina no només corresponen a dones joves i llestes, sinó a qualsevol tipus de dona. Un cas d'intel-ligència i vellesa és el de la protagonista de «Sa jaia Gri» del tipus C-O72 ALC. M. IX (I996: 23-44). Tot i que no es caracteritza per la seva bondat ni pel bon comportament - la jaia s'enginya per vendre la somada de mongetes i els ases de dos homes amb els quals comparteix el camí cap a Palma i per quedar-se els diners per fer la caixada de la seva filla que s'ha de casar-, el to de la rondalla indica que és tinguda en compte com a referent de llestesa molt per damunt del de les figures masculines «És ver que aquell amo i aquell hortolà eren un poc tocats de sa caixa de Sant Pere i no acabaven de tenir sa vivor que s'és menester per anar pel món. És ben cert que sa jaia Gri los donava set voltes: hi veia més d'adormida que ells dos de desperts» (I996: 23). També 
ho troben els altres com el senyor de la Diputació on ha duit els dos homes que s'exclama: «-El dimoni és aquesta jaia! No hi ha remei! Los guanya de massa, a polissonada, an aquests dos beninonis!» (I996: 40).

Les jaies representen la veu de l'experiència i sovint se'ls demana ajut i consell, moltes vegades apareixen en moments clau per fer de salvadores de qui està en perill. En trobam un doble exemple en «Es Castell d'Iràs i no tornaràs» ATU 3I3C ALC. GG. I (I996: 499-527). Per una part, en la versió impresa, quan l'àguila deixa en Bernadet a terra ferma, on hi ha el Castell d'Iràs i no tornaràs, li aconsella que vagi cap a unes casetes blanques a s'entrelluu: «-Veus aquelles casetes? —diu s'àliga-. Idò allà has d'anar. Hi trobaràs una jaia de cinc-cents anys. Per amor de Déu, fé lo que et dirà, i trobaràs es castell que cerques. Tots es que hi són venguts, i no l'han creguda, no los han vists pus». L'àguila és l'única de tots els animals, de la terra, de la mar i de l'aire, que ha sabut on havia d'anar a cercar aquest Castell. Ha sabut més que els tres ermitans tan vells. La jaia els supera tots i ella és la clau per poder sortir viu de l'aventura en la qual es troba immers en Bernadet.

La jaieta és la passa posterior als tres ermitans en la versió impresa que, en aquest apartat, segueix el manuscrit corresponent a la contadora Catalina Tomàs Pinya ALC. Lta. III (3-8). Però, en una altra versió del contador Antoni Garrit ALC. Lta. III (309-3I7), en Bernadet, a més a més de la jaieta que l'informa sobre les filles del rei, anteriorment, s'ha trobat amb tres jaietes en lloc de tres ermitans, que són les reines dels animals verinosos, dels peixos i dels animals volàtils, respectivament. 5

Les jaies mostren el pas del temps en el seu cos, solen anar amb sos morros p'en terra però són llestes i tenen la ment oberta per fer valer la seva experiència i donar consells i ajut a qui s'ho mereix, quan és necessari:

Un dia, ses d'un carrer escometeren una jaieta que estava a un llocarró i pujava clares vegades a la vila. Ja anava amb sos morros per sa terra, no tenia cap dent, però sí una llengo ben fresca i una vista que travessava i una cama de foc.

—Germaneta —li digueren aquelles dones—, i vós què hi deis an això? «La princesa bella» (ALC. GG. III [200I: 3I7]).

Així mateix, sol ser prou conegut de tothom que les jaies tenen coneixements extraordinaris i que poden ajudar en situacions complexes o de difícil solució, per això Alcover ens fa conèixer el pensament d'en Bernadet, l'heroi de «La princesa Aineta» ATU 402 ALC. GG. II (I998: 257-286), en relació amb aquestes figures. La jaieta agraeix a en Bernadet que l'hagi ajudada i s'ofereix en el que pugui servir: «Aquí En Bernadet se'n pensa una de bona. —Ses jaies — va dir — són el diantre per sebre coses de vegades. ¿Qui em diu que aquesta no sàpiga lo que jo fins ara no he pogut trobar? Poria esser molt bé que en sabés qualcuna, d'al-lota tal com jo l'he mester! Poria esser molt bé que em sabés donar camí per trobar-la!» (I998: 260). Efectivament, la jaieta és qui dóna les entresenyes a en Bernadet per trobar la princesa Aineta, l'al-lota que reuneix tots els requisits de bellesa, llestesa i xerevel-leria que el rei exigeix a la dona del fill que vulgui heretar la corona. Així, observam com les jaies — que solen ser donants i conselleres— ajuden l'heroi i l'heroïna a

5 És curiós que sigui la versió de l'home la que presenta les tres dones sàvies i reines de tots els animals, en canvi la versió de la dona - que és la que finalment preferí Alcover- es refereix a figures masculines com a ermitans i reis dels animals. 
trobar el que cerquen. Poden ser clarividents i fades, i usen els seus poders per ajudar les altres persones que ho necessiten, generalment per altruisme, però, en algunes ocasions, apareix en les rondalles la figura de la jaia dolenta, que representa la cara fosca dels poders extraordinaris i que s'acosta a les bruixes.

\section{La intel-ligència i l'enginy}

Un exemple d'intel-ligència pràctica de la dona és el que apareix en «Una madona que enganà el dimoni» ATU II75 ALC. M. XIII (I995: 43-52). La madona reacciona davant la dificultat amb enginy i astúcia, i no dubta a posar-se al lloc del seu marit perquè confia en la seva pròpia capacitat per guanyar les messions i fer tornar arrere el pacte amb el dimoni, segons el qual el seu marit li ha d'entregar l'ànima. També és molt llesta na Joana, la dona d'«En Pere de sa xuia», ATU I3I9-I38IB ALC. M. XVII (I996: 7-20), que, quan sap que el seu marit ha mort el batle, s'anticipa al que passarà i tira un xot dins el mateix pou i faves i xuia per la finestra. D'aquesta manera, quan la Justícia de Ciutat el va a cercar, no el se'n duen, perquè ella pot demostrar que és més beneit del que és en realitat i el deixen anar. És la intel-ligència de na Joana el que fa que s'alliberi d'anar a presó i la rondalla deixa entreveure que, només quan ell segueix les instruccions de la dona, les coses es componen.

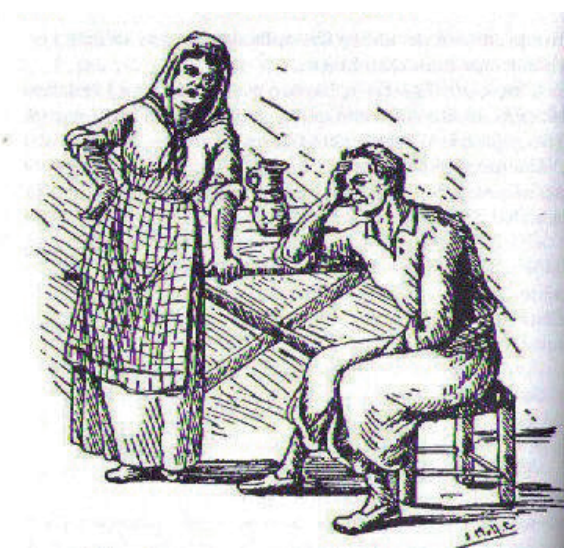

[Imatge 3: «Una madona que enganà el dimoni»]

En «Ressonàncies de l'Antic Testament: I7. Es pas del Rei Salomó», ATU 2I7 ALC. M. V (I997: 42-44), Alcover ens mostra com la intel-ligència masculina i femenina funcionen de manera diferent. En aquest episodi, el magne i intel-ligent rei Salomó és enganyat per dues jovenelles que el deixen penjat dins un covo al costat de la seva finestra perquè les vol festejar. El missatge que se'ns dóna és que el rei Salomó és un savi i sap donar grans consells, però, la intel-ligència i l'enginy femenins el guanyen i el deixen en ridícul. Un cas ben diferent de descripció del mateix personatge el trobam en «Es conseis del Rei Salomó», ATU 9IoB ALC. M. IV (I995: 50-59), on és descrit com un model de saviesa masculina per excel-lència. El personatge bíblic és conegut i admirat pels seus consells, i això fa que es converteixi també en un personatge més de l'imaginari popular. Salomó dóna tres 
consells al seu criat, Toniel-lo, que li costen tres mil lliures, el sou de deu anys de feina al seu servei. Aquests consells, però, li salven la vida dues vegades i l'aturen de cometre un parricidi, per la qual cosa ell els dóna per ben pagats. Així mateix, el final de la rondalla mostra la noblesa del rei que li ha regalat una panada on hi ha amagades les tres mil lliures.

En «Na Joana i la fada Mariana», ATU 428 ALC. GG. III (200I: 254-260), apareix una reina sàvia que, quan sap que passegen una al-lota «que diuen que sap tant com Vossa Reial Majestat», vol «llevar-la d'es mig perquè no volia que negú sabés tant com ella». Si en «Na Magraneta», ATU 709 ALC. GG. VI (20I3: 260-272), observàvem una competència entre una dona jove i una d'adulta - mare i fillaper motiu de bellesa, en «Na Joana i la fada Mariana», ATU 428 ALC. GG. III (200I: 254-260), la competència es produeix entre una de jove i una d'adulta — futures sogra i nora- per motiu d'intel-ligència. Tanmateix, els reptes que la fada Mariana proposa a na Joana no són possibles sense la mà —el guant màgic que li dóna per cridar-lo- d'en Bernadet, que fa servir criatures meravelloses - homenets i donetes de colzada- que poden dur a terme qualsevol tasca impossible per a una persona.

Una altra jove que esdevé modèlica per la seva intel-ligència és la protagonista de «Na Blancaflor» ATU 3I3A ALC. GG. I (I996: 479-495), ja que ella és qui dóna les instruccions a en Joanet per poder-se alliberar de les males arts de son pare, el dimoni. Na Blancaflor l'adverteix: «Si m'escoltes i fas lo que et diré, seràs escàpol de ses seves ungles» i la resposta d'en Joanet és immediata i incondicional: «Promet que t'escoltaré, però de tot, i que faré tot quant me diràs!». Al llarg de la rondalla, en Joanet hi ha d'acudir per poder superar les proves que el dimoni li posa en forma de feines i ella té la solució per a situacions impossibles. També és ella qui es transforma i el transforma a ell per seguir fugint del dimoni i, justament, quan ell no fa el que ella diu —com és no agafar el cavall més magre—, s'equivoca i això té males conseqüències per a ambdós. Quan ell insisteix que es giri per dir adéu a son pare, l'arriba a convèncer, i el mal pare arriba a badar-la i la deixa inert. La rondalla explicita com són d'intel-ligents les dones d'aquesta rondalla quan na Blancaflor fuig amb en Joanet i el dimoni s'enfada:

Se posa a cridar com un boig, movent un escàndol fora mida. Sa seva dona, que sabia set vegades més que no ell (i Na Blancaflor set vegades més que no sa mare), li diu:

—Es cridar és debades: és fuita amb En Joanet! I amb so cavall que corr com es vent! Tu pren es que corr com es pensament, i al punt els aglapiràs, si no paupes ni bades massa.

El dimoni, ja ho crec que l'escoltà (ALC. GG. I [1996: 49I]).

El dimoni sap que les dues dones li guanyen de massa en intel-ligència, i per això obeeix cegament el que la seva dona li aconsella. Així i tot, na Blancaflor l'enganya encara per dues vegades més i la seva dona li ha de desvetllar com ho ha fet la filla.

En «El Príncep Corb», ATU 425A ALC. GG. III (200I: 26-70), l'heroïna ha d'apagar set ciris amb un sol buf que es troben separats damunt una taula molt gran per poder desencantar el seu marit. El Príncep Corb pensa que és una missió impossible, però ella usa la seva intel-ligència per pensar la manera com fer-ho: «Com Na Catalina sent això, se posa pensa qui pensa, pensa qui pensa, fins que 
a la fi se pega un cop an es front i diu: -Ja sé què faré! Ja ho sé! Ja ho sé! No hi ha un canyar per ací prop?» (200I: 58). El príncep segueix dubtant i li qüestiona: «Però què l'has de reprémer?», tanmateix ella es mostra segura de la seva idea i de la capacitat que té d'executar-la i li respon: «—Tu deixa'm fer — diu ella—. Mostra'm es pas per anar an es jardí» (200I: 59). A mesura que ella va preparant el seu enginy, el príncep cobra coratge i li reconeix el mèrit: «—El dimoni ets — diu el Príncep Corb, com veu aquell acudit».

Així com hi ha pensadores positives i que serveixen com a model humà de referència, també hi ha casos d'altres dones que fan servir la intel-ligència en benefici propi o per fer mal els altres com en «En Bernadet i la reina manllevada» ATU 462 ALC. GG. III (200I: 359-379). La jove reina, suplantadora de la primera gràcies a les seves males arts, pensa com ho pot fer per matar el seu fillastre perquè no li faci ombra davant el rei, tot i així en Bernadet és l'heroi i, com a tal, rep els consells de la jaieta que l'orienten per superar les proves que ella li posa. Com que en les rondalles qui fa el bé és qui guanya, la reina manllevada, amb la seva bellesa i intel-ligència, es converteix en un antiexemple.

\section{Intel-ligència femenina i símbols}

Són molts els camins per convertir en símbols els elements i les condicions que envolten les figures femenines. Clarissa Pinkola Estés, psicoanalista d'arrel jungiana, considera que els símbols femenins poden estar vinculats a les jaies, que anomena «la Vieja» o «La Que Sabe», la «Gran Madre» o «La Loba», que considera «el símbolo de la raíz que alimenta todo un sistema intuitivo» (2008: 36-38). Des del punt de vista simbòlic, creu que «Hay que ver en la figura de la vieja la quintaesencia de la mujer de dos millones de años de edad. Es la Mujer Salvaje original que, aun viviendo bajo tierra, vive arriba». Per a ella, posseir les llavors, per exemple, és tenir la clau de la vida, per això afirma que «Es la encarnación de la Madre de la Vida y la Muerte en su forma más antigua y original» (2008: 42).

En la mateixa línia parla la també psicoanalista jungiana, Marie-Louise von Franz, tot lloant les figures femenines de les rondalles que simbolitzen el coneixement que prové de la intuïció i que pot arribar a estadis superiors. Afirma que les dones són capdavanteres i que, fàcilment i intensa, s’identifiquen amb nous moviments filosòfics o de pensament:

Il est mythologiquement juste de dire que les femmes sont davantage en harmonie que les hommes avec les idées dans leur état naissent. Elles y trouvent plus de liberté et peuvent y communiquer avec les contenus réprimés de l'inconscient qui commencent à émerger. De nombreuses civilizations connaissent ce type de prêtesse, voyante, médium qui sait "sentir le vent" et prédire le temps qu'il fera ou les événements futurs (I984: 2I3).

Fins i tot alguns autors, com Joseph L. Henderson (I995), consideren que es reserva a la dona la posició d'acompanyar els més joves com a protectora i model. En relació amb el viatge solitari o de peregrinació espiritual de l'iniciat a través del qual coneix la naturalesa de la mort, explica: 
Pero esta no es la muerte como juicio final $u$ otra prueba iniciatoria de fuerza; es un viaje de liberación, renunciación y expiación, presidido y mantenido por cierto espíritu de compasión. Este espíritu se suele representar por una «maestra» más que por un «maestro» de iniciación, una figura femenina (es decir, anima) tal como Kwan-Yin en el budismo chino, Sofia en la doctrina gnóstica cristiana, o la antigua diosa de la sabiduría, Palas Atenea (Henderson I995: I52).

Un bon exemple de símbols de saviesa són les tres àligues que tenen el niu damunt un pi sota el qual dormen el rei i el senyor moro, i les seves converses són el punt de referència que serveix al segon per fer camí i trobar el personatge cercat, que és s'Hermosura del món. Elles són les que fan l'advertiment següent: «qui parlarà o motarà un tros de pedra mabre tornarà» (2006: 245). També són àligues les que té el tercer ermità al seu càrrec en «En Joanet i sa donzella desencantada» ATU 425P 302 ALC. GG. III (2OOI: I33-I57), i només una, l’àliga de Portugal, sap on para el barranc del porc senglar que cerca en Joanet. Al final tornen a aparèixer vuit àligues per tirar la carossa que se'n durà la princesa, la seva dama i en Joanet cap al regnat dels pares d'ella.

L'instint femení és també una mostra de saviesa com el de les gegantes que coneixen en Bernadet i el saluden pel seu nom quan el veuen arribar. Les jaies tot ho saben, són també pous de saviesa, susceptibles d'anar-hi i consultar-los sobre el que sigui: per exemple, la jaieta de «La princesa bella» ATU 434 ALC. GG. III (200I: 3I3-333), a la qual acudeixen les veïnes per demanar-li parer sobre el que passa a la filla del rei. Elles representen la veu de l'experiència i, alhora, el conjunt dels dons de la intel-ligència femenina que els aporta un caràcter màgic al servei de l'heroi o de l'heroïna, o simplement de qui necessita adjutori.

La saviesa de la dona prové, essencialment, del seu contacte amb la natura i dels seus poders naturals. No cal ser heroïnes sàvies com na Blancaflor o na Fadeta, sinó que la condició de dona és suficient: «dans le conte, le pouvoir féminin se présente comme un tout, indissociable de toute femme. Contrairement à la Sybille ou à la Pythie qui avaient pour fonction de lire l'avenir, la femme conjugue spontanément et aisément de nombreux pouvoirs qui s'imbriquent et lui composent une réélle puissance: sur la Nature, comme sur le Destin» (Piarotas I996: I03).

De vegades, els valors femenins de saviesa i prudència es mostren a través de figures animals com en «Es rossinyol i sa rossinyola» ATU 245 ALC. GG. I (I996: I55I57). El rossinyol viu feliç, però li falta companyia i decideix cercar parella. Troba una rossinyola en un lloc més pobre i li ofereix bon menjar per convèncer-la que vagi amb ell. Ella, com si d'un negoci es tractàs, li respon «-Feta està sa barrina!» (I996: I56). Durant un temps viuen feliços i canten panxa plena, però l'amo dels cirerers els envesteix amb una escopetada que frega la pell de la rossinyola i li toma algunes plomes. La rossinyola pren la determinació de tornar-se'n allà d'on venia:

I ja li va haver estret ben afuada, i de d'allà.

—Espera! Espera, dona! —deia es rossinyol encalçant-la-. No sies tan poruga, que no hi ha tant per tant tampoc! Ell no ho paga es parlar-ne per un parei de plomes! Si an això mos hi veim cada dia!

—Però no m'hi vui veure jo! — deia sa rossinyola volant com la bala.

—Però si només és estat un retgiró! — deia ell. 
- No ho he de mester sebre...! A ca meua me'n vaig, abans de pus raons! M'estim més es quatre mosquits i llavoretes d'es torrent de Sa Branca, allà on ningú me diu fé't ençà fé't enllà, que no totes ses cireres i es cirerers de Son Selles.

Ell es rossinyol no la pogué ginyar a tornar arrere (ALC. GG. I [1996: I56]).

El missatge de la rondalla és ben clar en el sentit del seny i la prudència de la rossinyola que prefereix la tranquil-litat i la pau a un excés de menjar envoltat de perills. La determinació de la figura femenina en la presa de decisions és exemplar i no hi valen els motius de la figura masculina per fer-la canviar de parer.

En «Es dotze mesos i dues jaies», ATU 480 ALC. GG. III (200I: 43I-458), podem observar com les dues jaies constitueixen dos exemples indiscutibles de saviesa femenina. De boca de les dues dones sorgeixen els coneixements propis de tots els detalls del transcurs de l'any, i per extensió, de tota la vida. Elles representen la veu de l'experiència, tant des del caire positiu com des del negatiu, i saben argumentar les seves afirmacions per tal de convèncer qui les escolta. En el seu discurs hi caben frases fetes, refranys, gloses, anècdotes i experiències viscudes, i tot és explicat amb precisió i riquesa de paraules i expressions.

\section{En conclusió}

En les rondalles d'Alcover trobam exemples nombrosíssims de dones intel-ligents que es mostren com a pensadores, i el seu criteri és respectat i valorat per tothom. És una manera de demostrar que les dones no són tengudes en compte només pel seu aspecte físic o per la seva bellesa, sinó que se les valora per les qualitats intellectuals que posseeixen. Alcover descriu amb detall com ho fan per pensar i com aconsegueixen vèncer l'adversari masculí a través de la intel-ligència.

En ocasions, a causa d'una lectura poc aprofundida, s'han atribuït a les rondalles uns esquemes de pensament i de comportament masclistes, que podem trobar en l'Aplec en escasses ocasions. El que sí que predomina és el paper actiu i destacat de la dona com a personatge de les rondalles alcoverianes. Es tracta de dones que han après, al llarg de generacions, de l'observació i el contacte amb la natura, i del fet de ser presents en els moments clau de la vida humana. El canonge valora i respecta la dona pensadora i la posa com a exemple que cal seguir per als homes i les dones que l'envolten.

En nombroses ocasions, el rei s'enamora de la jove que vol convertir en la seva esposa perquè el supera en intel-ligència, però no només trobam exemples de llestesa femenina en dones joves i belles, sinó en qualsevol tipus de dona com les fades, les madones o les jaies. Elles usen la seva capacitat de pensar tant per a efectes positius com negatius, tot depèn de cada circumstància. També l'empren de manera pràctica i enginyosa per sortir de situacions complicades, tant elles com el seu marit o la seva família.

La dona de les rondalles, igual com ha passat a la vida real, ha hagut de crear estratègies a fi de poder sobreviure dins un món de paràmetres andrògins per no perdre la personalitat pròpia, i ha usat l'astúcia, el silenci o la persuasió per poder escapar de situacions perilloses i desagradables. D'aquesta manera, es compensa el pes de la tradició que durant segles ha intentat subjugar la dona al poder dels valors masculins i es planteja una neutralitat que iguala les persones i que posa al mateix nivell el costat masculí i el femení. 
No hi ha objeccions possibles a la superioritat intel-lectual de determinades dones i l'opció correcta és creure el que diuen i fer les coses segons les seves instruccions. La saviesa de les dones es pot mostrar directament a través de la descripció dels seus actes o del procés de pensament, o també indirectament a través d'alguns símbols, com l'àguila, o de representacions en forma d'animals. Les dones intel-ligents solen superar els homes intel-ligents, per això elles tenen la darrera paraula, la definitiva.

\section{Referències bibliogràfiques}

Alcover, Antoni M. (I936-I972): Aplec de rondaies mallorquines d'En Jordi d'es Racó. Volum I a XXIV. Palma: Editorial Moll.

- (I996-20I7): Aplec de rondaies mallorquines d'En Jordi d'es Racó. Volum I a VII. Edició a cura de Josep A. Grimalt i Jaume Guiscafrè. Palma: Editorial Moll.

- (s. d.): Alcover notes de rondaies I, II, III, IV i VI i Notes preses al vol dels contadors de rondayes $V$. Llibretes originals manuscrites.

Alcover, Antoni M.; Borja Moll, Francesc de (I980): Diccionari català-valencià-balear. Palma: Editorial Moll. Disponible en línia: <http://dcvb.iecat.net/> [data de consulta: agost de 20I7]

DENISSENKO, Gala (I999): «"Una prova difícil de resoldre”, tema comú en les rondalles catalanes i russes protagonitzades per dones». Dins Actes de l'Onzè Colloqui Internacional de Llengua i Literatura Catalanes, Palma (Mallorca), 8-I2 de setembre de 1997. Barcelona: AILLC / UIB / Publicacions de l'Abadia de Montserrat, volum II, p. 453-46I.

Estés, Clarissa Pinkola (2008): Mujeres que corren con los lobos. Traducció de M. Antonia Menini. Barcelona: Ediciones B.

HARF-LANCNER, Laurence (I984): Les fées au Moyen Âge: Morgane et Mélusine, la naissance des fées. París: Honoré Champion.

- (2003): Le monde des fées dans l'occident médiéval. París: Hachette.

Henderson, Joseph L. (I995): «Los mitos antiguos y el hombre moderno». Dins Carl G. JUNG: El hombre y sus símbolos. Barcelona / Buenos Aires: Ed. Paidós, p. IO4-I57.

FrANZ, Marie-Louise von (I984 [1972]): La femme dans les contes de fées. Traducció de Francine Saint René TAILlANDIER. París: La Fontaine de Pierre.

LÜTHI, Max (I979 [1947]): La fiaba popolare europea. Forma e natura. Traducció de Marina CometTA. Milà: Mursia.

Piarotas, Mireille (I996): Des contes de femmes. Le vrai visage de Margot. París: Editions Imago.

RondCat: Cercador de la rondalla catalana. Arxiu de Folklore. Departament de Filologia Catalana de la Universitat Rovira i Virgili. <http://rondcat.arxiudefolklore.cat/> [data de consulta: agost de 20I7]

TEMPORAL, Josep (2OI4): «Notes programàtiques per a una valoració pedagògica de l'heroïna de la rondalla meravellosa». Dins Alexandre BATALleR; Margalida Coll: Literatura oral i educació: simbiosi i complicitats. Alacant: Grup d'Estudis Etnopoètics / Arxiu de Tradicions de l'Alguer, p. I77-I86. 
UTHER, Hans Jörg [ATU] (2004): The types of international folktales. A classification and bibliography based on the system of Antti Aarne and Stith Thompson. 3 volums. Folklore Fellows' Communications 284, 285, 286. Hèlsinki: Suomalainen Tiedeakatemia.

VALRIU LlinÀs, Caterina (I998): Influències de les rondalles en la literatura infantil i juvenil catalana actual (I975-I985). Palma: Editorial Moll.

VIDAl I AlCOVER, Jaume (I996): Estudis de literatura medieval i moderna. Recopilació i introducció de Pere Anguera i Magí SunYer. Palma: Editorial Moll.

ZIPES, Jack (20I4 [20I2]): El irresistible cuento de hadas. Historia cultural y social de un género. Traducció de Silvia Villegas. Buenos Aires: Fondo de Cultura Económica. 